NOTAS

\title{
Bridge 47 Target 4.7 Roadmap
}

Publication typology: Advocacy tool.

Responsibility: Bridge 47.

Author(s): Bridge 4.7 (with contributions of the participants of the Envision 4.7 Event, Helsinki, 6-7 November 2019).

Language: English.

Publication date: November 2019.

Pages: 4.

Acess: https://www.bridge47.org/node/241

\section{Presentation}

I. What is the Target 4.7 Roadmap? Introducing the Roadmap: main recommendation and strategy

It is a policy guideline for the future implementation of the SDG Target 4.7 in Europe. The main recommendation is that a pan-European overarching strategy needs to be developed at the latest by 2021 . To guide this European strategy, a multi-stakeholder group with relevant expertise needs to be established.

2. What is transformative education in the context of Target 4.7? How do we go about adapting education at all levels to Target 4.7 in Europe?

Target 4.7 reflects the transformative power of education by promoting global citizenship, sustainable development, human rights, gender equality, peace, and appreciation of cultural diversity. 
This calls for the creation of coalitions across Europe to find common ground amongst each of these components, to build on their strengths and identify and learn from their successes and failures. Transformative education should also include those who have been underrepresented and marginalized, and create/enable opportunities for practitioners/learners to build capacity, to upskill and to revisit assumptions/ worldviews.

3. How is that life-long learning is recognized in Target 4.7? How is that education, in its different iterations, support lifelong learning?

This target reflects the wide range of education available in all countries and recognizes that learners mentioned in SDG Target 4.7 include lifelong learners. Therefore, it is important to equally value all forms of education and support lifelong learning as they play an essential role in furthering equal opportunities, social inclusion, social cohesion and a sustainable future.

Formal: Teaching and learning that lead to formal certification or qualification that is recognized by relevant educational authorities.

Non-formal: Skill/qualification-based learning. Formally recognized but taking place outside a formal setting. Usually non-assessed, but sometimes offering a certificate.

Informal: Community/civic learning (e.g., attending marches or campaigning). Non assessed.

4. What is required in terms of cross-sectorial cooperation to achieve Target 4.7 ?

The scale and ambition of SDG Target 4.7 requires multilevel and cross-sectorial partnerships, with a need to bring together and engage a number of actors, including local and national governments, members of parliament, private sector, civil society, EU, Council of Europe, UN system, academics, media, youth and educators. This kind of engagement will address the need for improved cooperation and coordination across-European, national and regional levels across all policy areas.

5. What kind of indicators are required to measure Target 4.7? 
The discussion on which indicators are relevant to assess the implementation of 4.7 are important, as what is measured determines what gets implemented. The current global indicator on Target 4.7 is largely, but not exclusively, related to the formal education system. Efforts should be made to ensure that education undertaken in other settings (non-formal and informal) is fully recognized, as including lifelong learning as an indicator for 4.7 validates its importance.

In measuring progress, greater clarity on how 4.7 relates to local contexts is required, as this assists in determining the purpose of monitoring and assessment indicators, and captures the quantitative and qualitative changes required.

6. What competencies are needed for Target 4.7 to enable learners to become full citizens in their societies?

Education in all its forms plays an essential role in furthering equal opportunities, social inclusion and social cohesion, and has a fundamental role in developing the competencies that enable learners to play active roles as citizens in democratic societies and to support their personal development.

Competencies linked to Target 4.7 relate to learning, engagement and critical reflection, and the use of cognitive, affective and behavioral skills and understanding. Such competencies allow people to play active roles in the transformation of society at the global, national and local levels. Wide multi-stakeholder partnerships should be established to identify and further develop existing global and European competency frameworks.

7. Which resources are needed for Target 4.7 to be implemented? Which stakeholders should be included in funding strategies for SDG 4.7?

As Target 4.7. is key to the wider implementation of the 2030 Agenda, sufficient resources need to be ensured to enable and achieve its implementation across Europe. Such resources will include prioritization of target 4.7., dedicated and adequate funding, appropriate technology and the development of relevant capacities and capabilities.

Long-term funding strategies at European and national levels should be accessible to CSO's of all sizes, as well as financial and non-financial support within European countries for stakeholders focused on implementing 4.7. 
8. What is the role of the Knowledge Exchange Partnerships in the strategy for Target 4.7?

Experts participating in the regional Knowledge Exchange Partnerships of Bridge 47, facilitated by EADI, contribute with research and collaborative initiatives to the strategy of implementation of Target 4.7 at all levels. Academics, civil society members and policy makers make meaningful contributions based on the exchanges and paths for collaboration set in the Knowledge Exchange Partnerships. At present, three regional Knowledge Exchange Partnerships in the lberian, Northern Europe, and South Eastern Europe regions are actively committed to support evidence-based decision making on GCE in Europe and abroad.

9. How did the Iberian Knowledge Exchange Partnership and the other regional partnerships, in general, contribute to the elaboration of the Target 4.7 Roadmap?

Experts participating in the lberian Knowledge Exchange Partnership coordinated by Fundación ETEA, on behalf of EADI and Bridge 47, were present at the Envision 4.7 event in Helsinki, in November 2019, as others from the other regional Knowledge Exchange Partnerships. This event had a specific participatory methodology that allowed for the collection and harvest of inputs through theme-based working groups, plenaries and parallel sessions focusing on the specific components of Bridge 47 work. Issues of exchange and debate were, among others, indicators for measuring Target 4.7 and competencies for Target 4.7. Participants of the Iberian Knowledge Exchange Partnership (and the Northern and South Eastern Europe partnerships as well) contributed notably in this process and, as a consequence, the Target 4.7 Roadmap reflects the work of the Bridge 47 team and the extended network of like-minded allies who have been accompanying work on GCE in Europe in the last years. 